\title{
Изменение парадигмы образования по безопасности
}

\author{
Анджей Пьечивок *
}

\section{Введение}

В течение нашей жизни мы часто попадаем в ситуации, которые увеличивают вероятность того, что условия существования вокруг нас будут ухудшаться, а риск нарушения равновесия между системой наших ценностей и нашими возможностями будет увеличиваться. Такие ситуации могут оказывать существенное влияние на ощущения людей относительно безопасности жизнедеятельности. Среди множества процессов, отражающих современную реальность, похоже, что один в особенности преобладает над другими: это глобализация. Ее неизбежность и всеохватность видны не только в сфере производства и торговли, но и на уровне ежедневного опыта. ${ }^{1}$

Похоже, что современный мир постоянно создает такие угрозы для нашей безопасности, которые отличаются от опасных физических, химических и биологических факторов, приводящих к профессиональным заболеваниям или несчастным случаям. Профессиональные заболевания, которые долгое время были причиной разных форм инвалидности, сейчас все чаще ассоциируются с эмоциональной нестабильностью, страхом и депрессией. Мы живем в мире постоянных и быстрых изменений, в мире, который предлагает нам свободу и все более близкие контакты с другими людьми, - в основном благодаря развитию глобальных систем коммуникации и исключительно быстрому развитию масс-медиа. Однако в то же время мы живем в мире, который часто действует против нашего чувства безопасности. ${ }^{2}$

Статус образования, как большая надежда настоящего, сам по себе подвергается риску, так как он является объектом многих противоречий, трений и неуспехов. Сегодня мы становимся свидетелями снижения престижа многих гуманитарных, общественных и культурологических дисциплин из-за мировоззрения, основанного на механическом или психологическом редукционизме. Образование яв-

Подполковник доцент Пьечивок - кандидат гуманитарных наук и доктор общественных наук. Он член преподавательско-профессорского состава Национального Университета Обороны, Варшава. Его исследования направлены на проблемы, связанные с командирскими умениями офицеров: командиров и лекторов, а так же на проблемы, связанные с образованием по безопасности и с системами образования в Европейском Союзе и в HATO.

1 Процесс глобализации был описан особенно эффективно Джоном Найсбитом и Фрэнсисом Фукуяма. Смотри John Naisbitt, Megatrends (Poznań: Zyski i S-ka, 1997), 80-105; Francis Fukuyama, “Globalizacja bez końca," Gazeta Wyborcza 11 (2000): 23; Gordon Dryden and Jeannette Vos, Rewolucja w uczeniu, trans. B. Jóżwiak (Poznań: Zyski i S-ka, 2003), 49.

2 Смотри J. A. Pielkowa, "Pedagogika społeczna wobec zagrożeń współczesności,” in Człowiek u progu trzeciego tysiąclecia. Zagrożenia i wyzwania, vol. I., ed. M. Plopa (Elbląg: Elbląska Uczelnia Humanistyczno-Ekonomiczna, 2005), 61. 
ляется социальным процессом, организованным для осуществления процесса изменения в людях. С одной стороны, образование должно подготовить людей к использованию достижений цивилизации, а с другой стороны, оно должно вести их к творческому участию в дальнейшем развитии цивилизации. Это особенно важно при поиске научной истины и при формировании про-социального и про-мирного отношения. Современный мир требует, чтобы образование формировало креативность в человеке, обеспечивало механизмы, способствующие творческому мышлению, и помогало учащимся воспринять творческую точку зрения на мир, как нечто, что человек может изменить и трансформировать.

При нынешних глобальных условиях взаимная зависимость локальной и глобальной сферы дает основную модель развития и направление для творческой человеческой деятельности. Как на локальном, так и на глобальном уровне образование направлено на формирование и развитие уровня знаний в обществе. В этой статье рассмотрены некоторые темы и исследования, касающиеся реализации образования по безопасности на всех уровнях учебных программ. Анализ в основном сфокусирован на содержании, преподаваемом в средних и старших классах средней школы.

Йежи Куниковски пишет: «Основная цель школы состоит в образовании современного человека, обладающего набором стойких этических убеждений, который можно назвать сформированным сознанием, и набором убеждений о себе, своей идентичности и готовности». ${ }^{3}$ Хотя обычно безопасность не воспринимается как часть учебной программы начальной и средней школы, это не означает, что учебные заведения такого уровня не играют важную роль в образовании по безопасности. Школа, являясь критически важной образовательной институцией, не может оставаться вне основного течения мышления, направленного на улучшение безопасности. Общей целью школьного образования является формирование и повышение информированности молодых людей, которые должны быть в состоянии быстро и аккуратно не только предотвращать разные опасности, но также активно участвовать в деятельности, связанной с обеспечением безопасности в социальном окружении.

\section{Безопасность как категория образования}

После конца Холодной войны концепция безопасности развивалась скачкообразно и неравномерно. Претерпев глубокие трансформации и будучи расширенной транснациональными измерениями, сейчас концепция безопасности ориентирована как на безопасность человека, так и на глобальную безопасность. Концепция безопасности человека отличается от традиционной концепции безопасности как из-за факта, что угрозы исходят и изнутри, и вне государства, так и своей целью, которой является защита отдельных людей. Глобальная безопасность, которая включает безопасность человека, учитывает набор взаимосвязанных невоенных рисков - экономические кризисы, низкий уровень развития, ухудшение экологии,

3 Jerzy Kunikowski, Przygotowanie obronne społeczeństwa (Warsaw: Bellona, 2001), 140-41. 
- которые перешагивают государственные границы, и прежде всего, находятся вне возможностей регулирования государством.

Новые концепции безопасности в целом ассоциируются с уменьшением суверенитета отдельного государства. С одной стороны, индивидуальные граждане заменили государство в качестве основных держателей права на безопасность, а с другой стороны, задачу создания безопасности «sans frontieres» (без границ) взяли на себя международные институции и организации.

Безопасность как первейшая ценность человеческого существования является одним из основных объектов дискуссий как в рамках отдельных академических дисциплин, так и в более широком смысле в обществе. Она является объектом заинтересованности, стремлений и желаний людей по всему свету. В нынешней международной среде очень важно способствовать действиям, которые направлены на сохранение мира. Эти операции обусловлены характеристиками человеческой природы, а с другой стороны, аксиологией, или наукой о ценностях. Природа человека является предметом изучения как для философии (антропологической), так и для психологии (которая в деталях исследует личность, склонности, развитие и возможности человека). Система ценностей, с другой стороны, является областью изучения для аксиологии, основной части философии. Этика прежде всего устанавливает кардинальные ценности, которые связаны с личностью взрослого человека. Личность есть атрибут человека как сущность, которая главным образом дает ему свободу реализовать свое достоинство, потому что он озабочен великими вопросами. С древних времен такой философский человек является моделью для каждого аспекта этики и служит важным идеалом в любой ответственной и честной системе образования. ${ }^{4}$

Безопасность, в соответствии со строгой дефиницией понятия, означает состояние отсутствия угроз, состояние спокойствия и определенности. В разных дисциплинах этот термин используется по-разному, а потому его трудно дефинировать. В наиболее общем смысле, это состояние, в котором отдельный человек, социальная группа, организация или нация не ощущает угрозу для своего существования или для своих основных интересов. Безопасной является ситуация, в которой есть юридические, институциональные и практические гарантии защиты. В этом плане, безопасность можно воспринимать в эмоциональном, персональном, публичном, финансовом, экономическом, социальном и международном смысле. 5

В литературе безопасность труда чаще всего ассоциируется с гигиеной, понимаемой в целом как набор условий, которые имеют положительное влияние на здоровье человека. ${ }^{6}$ Поскольку это понимание безопасности труда слишком общее, оно может включать физические и эмоциональные компоненты. Словарьсправочник для учителей курсов профессиональной квалификаџии фокусируется

4 J. Świniarski, "Przywództwo jako osnowa edukacji dla bezpieczeństwa," Zeszyty Naukowe AON 1 (2001): 134.

5 Смотри http://leksykony.interia.pl/haslo?hid=173930.

6 Смотри M. Szymczak, ed., Stownik języka polskiego, vol. I. (Warsaw: PWN, 1978), 147, 740. 
на чересчур техническом определении: профессиональное здравоохранение и безопасность труда - это «набор средств и мер: технических, санитарных и гигиенических, социально-экономических и организационных, которые путем устранения или ограничения вредных и опасных физических, химических и биологических факторов, оказывающих влияние на рабочих в процессе труда, обеспечивают условия труда и окружающую среду, которые устраняют возможность возникновения профессиональных заболеваний и несчастных случаев на работе ...».7

Можно выделить две четко определенные точки зрения на безопасность:

1. «Узкая» точка зрения, которую можно описать как отсутствие угроз, сосредоточившись на анализе влияний на объект в терминах угроз для существенных внутренних ценностей.

2. «Широкая» точка зрения, которая третирует безопасность как формирование условий, позволяющих достижение высокой вероятности выживания, владения собственности и свободы развития; существенным аспектом здесь является обеспечение творческой активности субъекта или способность раскрываться навстречу и сотрудничать с окружением. ${ }^{8}$

На макроуровне безопасность рассматривается как реальное условие для внутренней стабильности и суверенности государства, которое отражает отсутствие любых угроз (в смысле удовлетворения базовых экзистенциальных и бихевиоральных потребностей общества и статус надежности государства как суверенного субъекта в международных отношениях). ${ }^{9}$ В прошлом вопросы безопасности ограничивались политическими и военными аспектами, но современное представление о государственной безопасности включает экономические, экологические, социальные и этнические аспекты. Все еще действующими остаются такие угрозы для личной безопасности и безопасности структур, как нарушения экономического, политического, морального и правового порядка в обществе. Но как угрозы для безопасности рассматриваются и такие проблемы, как отсутствие понимания и желания считаться с верховенством закона у части людей и государств, или следование индивидуальным интересам любой ценой, не считаясь с общественным благом. Многие из этих угроз все еще не устранены, и они могут стать потенциальной причиной для новых конфликтов и войн, которые могут разрушать экономику, культуру и безопасность человеческих обществ. ${ }^{10}$

В сегодняшнем многополюсном мире параметры нового пейзажа безопасности особенно сложны. Они включают большое число процессов и акторов, причем у

7 E. Goźlińska and F. Szlosek, Podręczny słownik nauczyciela ksztatcenia zawodowego (Radom: Institute for Technology of Operation, 1997), 10.

8 M. Cieślarczyk, "Społeczeństwa i społeczności na przełomie wieków - od bezpieczeństwa kultury do kultury bezpieczeństwa?" in Bezpieczeństwo w perspektywie socjologicznej (Warsaw: WBBS, 2001), 31-32.

9 Смотри Stanislaw Dworecki, “Zagrożenia bezpieczeństwa państwa," in Słownik terminów z zakresu bezpieczeństwa narodowego (Warsaw: AON, 2002), 16.

10 Ryszard Rosa, Filozofia bezpieczeństwa (Warsaw: Bellona, 1995), 232. 
всех есть специфические потребности, интересы, идеологии и стратегии. В этом контексте характер риска как социального конструкта и увеличивающееся число ситуаций, воспринимаемых как рисковые, придает многостороннюю и неразрешимую амбивалентность отношениям риски-безопасность, затрагивающим саму сущность понятия.

Ключевым является факт, что постоянное расширение охвата понятия безопасности делает ее трудным для полного достижения. Проблема усложняется еще больше фактом, что во многих ситуациях теперь все труднее найти разницу между мерами безопасности и источниками риска. Более того, общественное мнение информировано о факте, что все меры безопасности являются и источниками риска не существует такой вещи как безопасная безопасность.

Любая человеческая деятельность может быть источником опасностей и рисков. Экономика является показательным примером. Хотя часто подчеркивают, что по-настоящему проблема глобализации касается не тех, кто в ней участвует, а тех, кто из нее исключен, увеличение инвестиций в регионы, находящиеся на грани конфликта или уже в состоянии войны, и консолидированная международная помощь во время послевоенных миротворческих инициативах создает не только новые возможности, но и новые риски и нестабильности. В результате необходимы большие объемы ресурсов и тщательное их управление.

Это парадоксально, но даже широко одобряемая защита безопасности человека, прав человека, прав меньшинств и осуждение преступлений против человечества - являющихся причиной для сильных брожений в организованных формах гражданского общества, спонтанных группах и даже в общественном мнении могут производить нежелательные последствия. Действительно, увеличенная общественная чувствительность может невольно стимулировать появление новых конфликтов. Все меньшинства могут стать источником внутренних конфликтов во имя равенства, человеческих и культурных прав, самоопределения (среди прочих) в надежде защитить свою этническую и религиозную идентичность и привлечь внимание и поддержку международного сообщества в пользу их политики автономии, независимо от того, на чем они основаны.

Понятие риска включает учет вероятности событий, а вычисление этой вероятности требует взаимосвязанного сочетания экспертных знаний, здравого смысла, мнений, оценок, показателей и других объективных и субъективных аспектов. Кроме того, все риски имеют социальное измерение. Таким образом, безопасность является общественным благом, которое так же имеет значительную символическую ценность.

Усиление ощущения безопасности граждан имеет связь с образовательным влиянием программ, которые способствуют формированию людей, уверенных в том, что они способны справиться с вызовами, которые ставит перед ними жизнь. Этого возможно добиться, создавая в людях высокую самооценку, в том числе путем подготовки к сознательному участию в жизни, к личной ответственности, к самопринятию, упорству и личной почтенности. Чем выше уровень нашей самооценки, тем более подготовлены мы к тому, чтобы справляться с нашими пробле- 
мами. Изменения, которые были осуществлены в образовательных программах, оказались полезными для развития желательных личностных качеств.

Основными целями таких образовательных программ в области безопасности являются:

- Получение знаний о процессах, связанных с безопасностью, в разных сферах человеческой деятельности и их теоретическая интерпретация

- Определение связей между причинами и следствиями при изучении безопасности и формирование гомогенного знания (общая теория безопасности)

- Понимание концепций, программ и предположений комплексной безопасности отдельного человека, наций и государств

- Выбор адекватных критериев для оценки национальной и глобальной безопасности. $^{11}$

В человеческой жизни безопасность является фундаментальным и необходимым условием для здравого и адекватного развития, а также для самореализации в социальной среде. Мы предполагаем, что состояние, которое мы определяем как «социальная безопасность», достигается, когда выполнены следующие условия:

- Существует гармония между стабильностью и нестабильностью в важных вопросах жизни

- Между предсказуемыми и непредсказуемыми событиями существует благоприятное соотношение

- Нет неблагоприятных изменений в уровне безопасности, которого достиг отдельный человек, в смысле карьеры, жизненно важных факторов и краткосрочных и долгосрочных планов

- Нет никакого внешнего контроля или вмешательства в индивидуальные ценности и частные действия отдельного человека. ${ }^{12}$

\section{Персональная небезопасность}

Сегодня отсутствие безопасности является наиболее широко обсуждаемой в мире темой. После событий сентября 2001, когда наиболее защищенная на земле страна стала объектом насильственных действий и оказалось, что ее территория не имеет иммунитета против социальных и человеческих потрясений, типичных для других стран, наше коллективное ощущение отсутствия безопасности драматически усилилось.

11 Там же.

12 Marek Rybakowski, "Kultura bezpieczeństwa na tle stanu bezpieczeństwa dzieci i młodzieży w ruchu drogowym," in Edukacyjne zagrożenia początku XXI wieku, ed. K. Pająk and A. Zduniak (Warsaw: Dom Wydawniczy Elipsa, 2003), p. 100. 
То, как мы переживаем отсутствие безопасности, зависит как от отдельного человека, так и от общих факторов, персональных и культурных, субъективных и объективных. Однако надо признать, что «небезопасность» весьма нечеткая категория, и возможно, ее можно было бы проанализировать более точно и дать ей более точное определение.

Естественно, нет такой вещи как абсолютная гарантия безопасности, ни внешней, ни внутренней, и очень часто вокруг вопроса, какова степень безопасности, которую в состоянии, или не в состоянии предложить нам те, кто в ответе за государство, ведутся политические битвы. Кроме того, даже в наиболее ограниченном смысле безопасность нельзя толковать как простую защиту безопасности граждан, а безопасность надо понимать, как систему для защиты их прав и обязанностей т.е. как глобальную правовую систему. В связи с этим надо сказать, что когда мы говорим о доверии к институциям государства, об их надежности и эффективности, мы в конечном итоге говорим об одном из элементов реальной безопасности.

В типичном постиндустриальном обществе темпы экономического роста ниже и более ненадежны, чем они были прежде. Технологические изменения означают, что устойчивая занятость в сфере производства уже невозможна в массовых масштабах, что имеет последствия для надежности рабочих мест низкоквалифицированных или неквалифицированных рабочих и для классовой структуры и политических интересов, связанных с этим. Эти изменения создают новые социальные риски и новые пути для реформ. Новые социальные риски - это риски, с которыми сталкиваются люди в течение их жизни в результате экономических и социальных перемен, связанных с переходом к постиндустриальному обществу.

Парадоксом критической образовательной ситуации является факт, что независимость, обусловленная упором на персональную независимость и персональную ответственность, или в определенной степени автономным образованием, может привести к изоляции. В таких случаях, автономия, как обязанность к себе считаться с общими нормами, исчезнет, превращаясь в злоупотребление автономией. Случаи такой «независимости» - с интенсивным фокусом на самого себя - наблюдаются, когда в процессе образования доминирует тенденция фокусирования на индивидуума.

Существенное влияние на качество процесса образования во многих социальных окружениях оказывает революция в сфере информационных технологий, которая, с одной стороны, принесла столько полезных вещей в нашу жизнь, а с другой, стала причиной глубокого культурного кризиса. Похоже, величайшим мифом нашего времени является миф о праве человека свободно выражать свою личность. Часто этот миф превращается в правило: каждый может делать все, что захочет, но не каждый и не все.

Современный человек, как сформулировал это Эрих Фромм, только думает, что знает, что он хочет; на деле, он хочет то, что его заставляют хотеть. В результате этого процесса он теряет свою идентичность, без которой нет настоящей без- 
опасности для свободной личности. Потеря идентичности усиливает необходимость адаптироваться к обязательным моделям. ${ }^{13}$

Один из факторов, которые дегуманизируют социальную жизнь и угрожают существованию человека, это нарушения удовлетворения основных потребностей человека. Такие нарушения, в смысле потребности в безопасности и устойчивости, по мнению экспертов, приводят к ослаблению ощущения целенаправленности жизни отдельного человека, что может породить обсессивно-компульсивные неврозы, снижение потребности более высокого уровня сосредотачиваться на проблемах, связанных с чувством порядка и проявлению тенденции искать поддержку в ком-то или в чем-то, что характеризуется постоянством.

При оценке ситуаций, с которыми мы сталкиваемся, страх играет существенную роль, так как он позволяет нам решить, принесет ли нам данное событие выгоды или будет иметь только отрицательные последствия. Однако, оценка не всегда бывает точной. Люди, страдающие беспокойством, квалифицируют некоторые угрозы как более опасные по сравнению с лицами, у которых уровень страха стабилизован. Однако, некоторые угрозы оцениваются как имеющие один и тот же уровень риска, независимо от отличий в интенсивности беспокойства между разными людьми. Наркотики, терроризм или взрывы бомб обычно вызывают сильную реакцию страха и оцениваются как элементы риска, тогда как деятельные виды отдыха, лыжи, плавание или верховая езда обычно описываются как относительно безопасные и не представляющие существенного риска. На оценку рисковой ситуации существенно влияет степень комфорта при разрешении задач, с которыми мы не сталкивались прежде. В таких ситуациях не известны никакие превентивные меры, которые позволили бы нам избежать отрицательных последствий опасностей. Лица, которые боятся провала при выполнении определенной задачи, обычно переоценивают связанный с этой задачей риск.

Как бы там ни было, похоже, что современное общество, которое является источником культуры индивидуализма и релятивизма, только способствует появлению нарциссических индивидуумов. Этот термин использован не случайно потому, что как заметил Ч. Делсол, «современный человек, даже взрослый, остается неустойчивым юношей, характеризующимся несогласованными желаниями, конфликтными мнениями, ... безответственностью». ${ }^{14}$

В современном обществе, отличающимся текучестью состояния, индивидуальные достижения не переходят в перманентное обладание собственностью, поскольку активы в мгновение ока превращаются в задолженности, и преимущества становятся слабостями. Обстоятельства, в которых надо действовать, проистекающие стратегии действий быстро становятся неактуальными. Опираться на преимущество опыта как источника знаний, и на стратегию и тактику, которые были эффективны в прошлом, неразумно, так как вызовы прошлого не учитывают внезапные, обычно неожиданные изменения обстоятельств. Прогнозирование буду-

13 Erich Fromm, Ucieczka od wolności (Warsaw: Czytelnik, 2000), 236-37.

14 Там же, 91. 
щих тенденций на основе прошлых событий еще более рискованно, и обычно ошибочно. Все более трудно получить надежные данные, а безошибочные предсказания стали просто немыслимыми. ${ }^{15}$

Пассивность является одной из наиболее типичных и патологических характеристик человека в современном обществе. Человек хочет, чтобы его кормили, но не желает двигаться, проявлять инициативу даже чтобы прожевать еду, которую ему обеспечили. Человек не относится творчески к тому, что он получил в наследство; он только собирает и потребляет. Оставаясь пассивным, человек не пытается найти свое место в этом мире, его заставляют отказываться от своих идеалов и связанных с ними требованиями к себе. Поэтому он чувствует себя бессильным, одиноким и полным беспокойства. Ему трудно определить себя, и его чувство целостности находится на низком уровне. Конформизм, который, похоже, выглядит единственным способом избежать невыносимого страха, часто оказывается недостаточным. ${ }^{16}$

Кроме пассивности, другим фактором, который часто оказывает влияние на индивидуальную безопасность, является послушание и подчинение. Сегодня послушание стало несколько забытой добродетелью. Послушание является спорной добродетелью, поскольку этот термин не понимают и часто путают с подчинением. Эта путаница между послушанием и подчинением является одной из наиболее опасных ошибок в современном образовании. Подчинение означает отказ от свободы, или капитуляцию. Послушание, с другой стороны, означает умение вести себя в соответствие с иерархическим порядком. Послушание есть применение собственной свободы, но не против вышестоящих; это выбор отношения сотрудничества с вышестоящим (учителем). Учителя - это те, кто назначены для организации жизни своих учеников. Те, кто отвечает за дисциплину, нуждаются в положительной реакции на свои действия со стороны своих подчиненных - иначе говоря, они нуждаются в послушании. Без послушания нет нормального образования. Невозможно организовать какую бы то ни было работу или нормально функционирующее общество. Поэтому воспитание в духе правильного понимания послушания является основополагающим для строительства свободного общества.

Сегодня в социологии стало модным заявлять, что человеческие проблемы могут быть анализированы без учета эмоций, связанных с ними. Предполагается, что научная объективность требует, чтобы мнения и теории, касающиеся людей, были свободны от эмоциональных связей. Надо подчеркнуть, что в Польше мы имеем дело с культурным вакуумом: с одной стороны, есть ощущение свободы, хотя с другой стороны мы сталкиваемся с материальной деградацией многих семей. Более того, во многих польских семьях мы наблюдаем феномен так называемой наследственной нищеты, и интенсификацию такого патологического поведения, как самоубийства, наркомания, агрессия и насилие. В современной семье увеличенный процент разводов, а также наличие отношений, официально не освещен-

15 Zygmunt Bauman, Plynne życie (Kraków: Literackie, 2007), 6.

16 Erich Fromm, Rewolucja nadziei. Ku uczłowieczonej technologii (Poznań: Rebis, 2000), 64. 
ных церковью или государством. В итоге, эта гибкость, которая приводит к открытым и временным связям, может привести и к принятию предательства в качестве нормального поведения. Она может привести к часто озвучиваемой позиции, что «если у каждого есть право жить как он хочет, значит, он может делать все, что он хочет. У тебя нет никаких обязанностей в отношение меня, и у меня нет обязательств перед тобой». В открытых и демократических обществах в образовании все чаще встречается применение этого правила.

Отказ от любой роли религии и церкви становится преобладающим, и основные жизненные ориентиры людей изменяются. Религия и этика все чаще становятся символом отсталости и препятствием для прогресса. Современное общество «сталкивается с особенным кризисом человечности», который отличается все большим отсутствием доверия к нашим собственным человеческим характеристикам, к нашему ощущению существования. В некоторых кругах мы наблюдаем исчезновение «универсального» - или универсально образованного - гражданина.

Развитие цивилизации (особенно в области технологии) усложняет жизнь во всех ее аспектах. У него есть как положительные, так и отрицательные последствия для человеческого развития; спектр угроз расширяется. ${ }^{17}$ Грань между сферой классических угроз (тех, что исторически постоянны и традиционны) и сферой свободы от угроз постепенно стирается и заполняется новыми категориями угроз, которые порождают сомнения в разнице между безопасностью и небезопасностью, между здоровьем и болезнью, между добром и злом.

Глобализация, информатизация и интернационализация общественно-экономической жизни являются сплетением зависимостей, которые имеют положительные и отрицательные последствия. Особенно турбулентными оказываются те, что напрямую влияют на людей и на основу их существования, в том числе на достойные, безопасные и здоровые условия труда.

Современность приносит нам как прогресс, так и новые явные угрозы. Давайте проанализируем влияние почти универсального доступа к информации. Похоже, мы становимся рабами технологии, которая должна была нас освободить. Хотя у нас есть доступ к беспрецедентному объему информации, мы становимся более дезориентированными, нежели хорошо ориентированными. Большая гибкость лишает нас гибкости вообще, и возможность большего выбора ограничивает нашу свободу. ${ }^{18}$ И что хуже всего, огромный и безостановочный поток информации заполняет любое пустое пространство и искривляет нормальное течение времени. Под постоянным давлением - или как бы сказал Томас Эриксен, под тиранией момента - мы обитаем в жизненном пространстве, лишенном понятий «раньше» и «потом», «здесь» и «там». На деле, даже «здесь и сейчас» в опасности, потому что следующий момент приходит так быстро, что становится трудно быть в моменте,

17 Такие угрозы связаны как с фактом индивидуального существования, так и со здоровьем (физическим и психическим) и с социальными функциями. Некоторые новые угрозы приводят к риску снижения уровня индивидуальных социальных условий.

18 Thomas Hylland Eriksen, Tyrania chwili. Szybko i wolno plynacy czas $w$ erze informacji (Warsaw: PIW, 2003), 13-14. 
который есть сейчас. Мы живем, уставившись на несколько секунд вперед в будущее. ${ }^{19}$

Давление времени не есть единственный источник напряжения для современных людей. Их действия не только являются объектом тирании момента, но мы так же сгибаемся под бременем выбора. Как говорил Энтони Гидденс, «жизнь в обществе, где царит риск, есть жизнь с аналитическим отношением к возможным действиям, положительным и отрицательным. ... Перед отдельными людьми в посттрадиционном социальном мире в каждую секунду раскрывается неисчерпаемое число потенциальных средств поведения (наряду с угрозами, их порождающими)».. ${ }^{20}$

Человек, который хочет продвигаться по карьерной лестнице в большой компании, зажат неопределенностью и беспокойством. Каждую секунду он может ошибиться и не достигнуть своих целей, став неудачником в глазах своей семьи и друзей. Это беспокойство усиливает его потребность в определенности. Если он потерпит неудачу, независимо от уверенности, которую дают современные методы принятия решения, по крайней мере ему не стоит обвинять себя. Человеку необходима надежность и в сфере мыслей, чувств и эстетических впечатлений. Благодаря широкому доступу к масс-медиа и образованию, человек быстро заучивает, какие мысли являются «хорошими», какое поведение является соответствующим, какие чувства являются нормальными и какие вкусы являются модными. Если люди сохраняют чувствительность к медиа сигналам, они могут быть уверены, что не совершат ошибок. Модные журналы говорят, нам в каком стиле мы должны одеваться, а читательские клубы указывают нам, какие книги стоит читать. ${ }^{21}$

Одной из самых значительных угроз для личной и структурной безопасности является дегуманизация образования. Постоянное давление желания добиться успеха, наряду с необходимостью работать при постоянной конкуренции и в условиях соперничества поколений приводит (в крайних случаях) к «макиавеллизации» поведения. Прагматизм преобладает над диалогом, разговором и рассуждением. В мире нового тысячелетия мы можем заметить опасную тенденцию в образовании создать «общество информации» за счет «общества образования». Внимание сосредотачивается на создании когнитивных способностей и ориентировано на проблемы современности и будущего вместо на преподавании ценностей, что потом может привести к неожиданным выборам и решениям, принимаемым группами или отдельными людьми. ${ }^{22}$

9 Там же, 11-12.

20 Anthony Giddens, Nowoczesność i tożsamość (Warsaw: PWN, 2001), 41.

21 Erich Fromm, Rewolucja nadziei (Poznań: Rebis, 2000), 78.

22 Среди экспертов усиливается ощущение, что есть фундаментальная и срочная потребность в обновлении прежних методов подготовки учителей. Учителей необходимо обеспечить более широкой гуманитарной основой - знанием педагогической, психологической, философской и социологической мысли - для тщательного изучения мира ценностей и их противоположностей, угроз, рисков и образовательных идеалов, для реализа- 


\section{Образование и безопасность}

В практике образования все чаще и чаще мы замечаем необходимость конструировать образовательный процесс таким образом, чтобы дать значимую позицию диалогу, который характеризуется взаимным пониманием участников. ${ }^{23}$ Отсутствие диалога или дискуссии, проводимой в атмосфере взаимного доверия, может на деле уменьшить пользу от многих образовательных действий учителей и родителей.

В связи с современными угрозами роль школы в этой сфере существенна. Из школьного обучения выходит большая часть содержания программ «образования по безопасности». Этот вид образования является одной из основных частей дидактического процесса и представляет собой набор превентивных действий, которые направлены на гражданское образование, коммуникации, здравоохранение и экологическое образование. Образование по безопасности является одной из областей, в которых обеспечивается подготовка для работы и жизни в современном мире.

Образование по безопасности включает образование в следующих областях: гражданское общество, экономика, право, оборона, социальные вопросы и окружающая среда. Это система образования, воспитывающая ответственность к жизни и здоровью как отдельных людей, так и всего общества. Ответственность должна проявляться в способности предвидеть результаты предпринимаемых действий; в способности помогать жертвам несчастных случаев и спасать человеческую жизнь; сознательно следовать нормам и законам государства; активно участвовать в мероприятиях по обеспечению безопасности на местном, региональном и государственном уровне; в участии в спасительных мероприятиях при природных бедствиях и техногенных авариях. В результате в образовательной системе Польши была принята новая обязательная формула для образования по безопасности. Конкретное содержание программ образования по безопасности реализуется в индивидуальных занятиях на различных этапах образования. Практика показывает, что наиболее легким методом предотвращения угроз является общий и систематический подход к вопросам образования.

Вот почему 21 октября 2008 года Министерство обороны и Министерство образования Польши подписали соглашение о сотрудничестве. Учитывая необходимость действовать совместно при реализации программ обучения в традиционных областях и в областях гражданского, патриотического и военного образова-

ции способности спорить и в итоге сотрудничать с молодыми людьми. В случае с Польшей есть ясно видимая асимметрия между ожиданиями и образовательными потребностями и их реализацией (желания применять новости и допустимых расходов). Образование должно облегчать восприятие реальности как набора ценностей, которые надо умело изучить и сделать своим внутренним достоянием так, чтобы их можно было бы использовать для формирования реальности и самих себя.

23 Tadeusz Siuda, ed., Kształcenie $i$ wychowanie młodzieży na rzecz bezpieczeństwa. Poradnik dla dyrektorów szkót i nauczycieli (Warsaw: ADAM, 2007), 27. 
ния школьной молодежи, Министерство образования и Министерство обороны договорились сотрудничать в следующих областях:

- Популяризация действий, направленных на формирование исторического, патриотического и оборонного сознания в военной и в школьной среде

- Стимулирование НПО, чтобы они предпринимали действия, включенные в гражданское, патриотическое и оборонное образование учащихся

- Поддержка и содействие инициативам, направленным на пропагандирование традиций польских вооруженных сил

- Предоставление организационной и материальной поддержки школам, которые названы именами личностей, связанными с традициями польских вооруженных сил, и школам, которые осуществляют расширенную программу «Образование для обороны»

- Популяризация идеи организации поездок по местам, которые являются частью военной истории Польши, организации спортивных мероприятий и военизированных палаточных походов

- Поддержка организации «Дней открытых казарм» и посещений комнат военных традиций, военных музеев и национальных исторических объектов

- Использование опыта организации патриотических мероприятий, школьных соревнований, состязаний по истории Польши, а также спортивных событий и военных соревнований

- Стимулирование школьной среды для участия в ежегодно организуемых патриотических событиях.

В целом, образование по безопасности в Польше осуществляется на трех уровнях: школьном, институциональном и общем. То, что мы стремимся осуществить в старших классах средней школы, это тридцать часов в год обучения по безопасности, причем количество часов в школе каждый год увеличивается. Это включает общее образование по безопасности наряду с образованием по средствам массовой информации, организациям и социальным ассоциациям, а также по органам безопасности - полиции, пожарным службам и вооруженным силам. Лучшие практики в области образования по безопасности требуют от нас преподавать безопасность и преподавать безопасно. 


\section{Литература}

"Przywództwo jako osnowa edukacji dla bezpieczeństwa." Zeszyty Naukowe AON 1 (2001): 134.

Bauman, Zygmunt. Plynne życie. Kraków: Literackie, 2007.

Cieślarczyk, M. "Społeczeństwa $i$ społeczności na przełomie wieków - od bezpieczeństwa kultury do kultury bezpieczeństwa?" In Bezpieczeństwo w perspektywie socjologicznej, 31-32. Warsaw: WBBS, 2001.

Dryden, Gordon, and Jeannette Vos. Rewolucja w uczeniu. Poznań: Zyski i S-ka, 2003.

Dworecki, Stanislaw. "Zagrożenia bezpieczeństwa państwa." In Słownik terminów z zakresu bezpieczeństwa narodowego, 16. Warsaw: AON, 2002.

Eriksen, Thomas Hylland. Tyrania chwili. Szybko $i$ wolno ptynacy czas $w$ erze informacji. Warsaw: PIW, 2003.

Fromm, Erich. Rewolucja nadziei. Ku uczłowieczonej technologii. Poznań: Rebis, 2000.

Fromm, Erich. Ucieczka od wolności. Warsaw: Czytelnik, 2000.

Fukuyama, Francis. "Globalizacja bez końca." Gazeta Wyborcza 11 (2000): 23.

Giddens, Anthony. Nowoczesność i tożsamość. Warsaw: PWN, 2001.

Goźlińska, E., and F. Szlosek. Podręczny słownik nauczyciela kształcenia zawodowego. Radom: Institute for Technology of Operation, 1997.

Kunikowski, Jerzy. Przygotowanie obronne społeczeństwa. Warsaw: Bellona, 2001.

Naisbitt, John. Megatrends. Poznań: Zyski i S-ka, 1997.

Pielkowa, J. A. "Pedagogika społeczna wobec zagrożeń współczesności." In Człowiek u progu trzeciego tysiaclecia. Zagrożenia $i$ wyzwania, 61. Vol. I. Elbląg: Elbląska Uczelnia Humanistyczno-Ekonomiczna, 2005.

Rosa, Ryszard. Filozofia bezpieczeństwa. Warsaw: Bellona, 1995.

Rybakowski, Marek. "Kultura bezpieczeństwa na tle stanu bezpieczeństwa dzieci $i$ młodzieży w ruchu drogowym." In Edukacyjne zagrożenia poczatku XXI wieku, 100. Warsaw: Dom Wydawniczy Elipsa, 2003.

Siuda, Tadeusz. Ksztatcenie $i$ wychowanie młodzieży na rzecz bezpieczeństwa. Poradnik dla dyrektorów szkół i nauczycieli. Warsaw: ADAM, 2007.

Szymczak, M. Słownik języka polskiego. Vol. I. Warsaw: PWN, 1978. 